\title{
Vestibüler Rehabilitasyonda Sanal Gerçeklik Teknolojisi
}

\author{
Rumeysa Nur AKBAŞ*
}

\begin{abstract}
$\ddot{O} \mathbf{z}$
Denge, vücudun ağırlık merkezini destek tabanı üzerinde tutma yeteneğidir. Dengenin sürdürülmesi, santral sinir sisteminin vestibüler, görsel ve proprioseptif sistemlerden gelen duyusal girdiyi koordine ettiği ve bütünleştirdiği karmaşı bir etkileşim ile sağlanır. Bu sistemlerden herhangi biri hasar gördüğünde veya yetersiz kaldığında, bireylerin denge işlevleri belirgin şekilde etkilenir ve baş dönmesine neden olur. Vestibüler bozuklukların tedavisinin temel dayanağı olan vestibüler rehabilitasyon, baş dönmesi, yaşam kalitesinin ve denge kontrolünün iyileşmesine olanak tanır. Vestibüler rehabilitasyon için sanal gerçeklik teknolojisinin kullanılması, daha gerçekçi ve sürükleyici bir ortamın simüle edilmesini sağlar. Bu sayede bireyin ilgisini daha fazla çekerek rehabilitasyona uyumunu artırır. Geleneksel vestibüler rehabilitasyon seanslarının uzun süreli ve maliyetinin yüksek olması, seans sırasında hasta kooperasyonu gerektirmesi gibi dezavantajlarından dolayı başarısızlıkla sonuçlanabilir. Sanal gerçeklik temelli vestibüler rehabilitasyon, geleneksel vestibüler rehabilitasyonun yerini alabilir veya katkıda bulunabilir.
\end{abstract}

Anahtar Sözcükler: Sanal gerçeklik, vestibüler hastalıklar, rehabilitasyon.

\section{Virtual Reality Technology in Vestibular Rehabilitation}

\begin{abstract}
Balance is the body's ability to keep its center of gravity on the base of support. Maintaining balance is achieved through a complex interaction in which the central nervous system coordinates and integrates sensory input from the vestibular, visual and proprioceptive systems. When any of these systems is damaged or insufficient, the balance functions of individuals are significantly affected, causing dizziness. Vestibular rehabilitation, which is the mainstay of the treatment of vestibular disorders, allows to improve dizziness, quality of life and balance control. The use of virtual reality technology for vestibular rehabilitation allows simulating a more realistic and immersive environment. In this way, it attracts more attention of the individual and increases his/her adaptation to rehabilitation. Traditional vestibular rehabilitation sessions may fail due to their disadvantages such as being long and costly and requiring patient cooperation during the session. Virtual reality-based vestibular rehabilitation can replace or add to traditional vestibular rehabilitation.
\end{abstract}

Keywords: Virtual reality, vestibular diseases, rehabilitation.

\section{Giriș}

\section{Vestibüler Sistem ve Vestibüler Rehabilitasyon}

Vestibüler sistem, vestibüler organ, oküler sistem, postüral kaslar, beyin sapı, serebellum ve korteks arasındaki iletişimi sağlayan ve duyusal organizasyonu içeren karmaşık bir yapıdır. Bu sistem, baş hareketlerini ve yerçekimi kuvvetlerini algılar, retina foveasındaki görüntülerin stabilitesini ve baş hareketleri sırasında postüral kontrolü sağlar ${ }^{1,2}$. Bu sayede üç boyutlu uzayda

Derleme Makale (Review Article)

Geliş / Received: 23.09.2021 \& Kabul / Accepted: 17.12.2021

DOI: https://doi.org/10.38079/igusabder.999714

${ }^{*}$ Arş. Gör., İstanbul Gelişim Üniversitesi, Sağllk Bilimleri Fakültesi, Dil ve Konuşma Terapisi Bölümü, İstanbul, Türkiye,

E-posta: rnakbas@gelisim.edu.tr ORCID https://orcid.org/oooo-0001-7868-1510 
oryantasyonu, kas tonusunun ve dengenin modifikasyonunu kontrol eder. Motor tepkilerin, göz hareketlerinin ve postürün koordinasyonu için gereklidir3. Vestibüler sistemde herhangi bir değişiklik olması durumunda vücut dengesi tehlikeye girer ve baş dönmesi gibi belirtiler ortaya çıabilir. Denge işlevinin yaş ile birlikte azalmaya başlaması düşme ve yaralanma riskini de artırmaktadır. Kişiye uygun egzersiz programı, denge işlevini geliştirebilir ve düşmeleri önleyebilir3,4.

Baş dönmesi ve vertigo terimleri, bakış, postür ve yürüyüşü etkileyen, hareket yanılsaması veya dengesizlik hissi gibi, uzamsal oryantasyon ve hareket algılama bozukluklarına ilişkin çeşitli semptomları kapsar5. Vestibüler sistem hasarına bağlı vücut dengesi bozukluklarının semptomu olan vertigonun yaşam boyu prevalansı \%7,4'tür. Vestibüler sistem bozukluklarında geleneksel terapötik yaklaşım, vestibüler rehabilitasyona ve semptomatik medikal tedaviye dayanır6. Vestibüler rehabilitasyon tedavisi; adaptasyon egzersizleri, substitüsyon egzersizleri, habitüasyon egzersizleri, statik ve dinamik denge egzersizleri, relaksasyon egzersizleri, fleksibilite egzersizleri, kas güçlendirme egzersizleri, proprioseptif egzersizler, kondisyon egzersizleri, postürografi eğitimi ve sanal gerçeklik eğitiminden oluşur. 1940'larda Cawthorne (1944) ve Cooksey (1946), vestibüler bozuklukların semptomlarını iyileştirmeye yönelik çeşitli egzersizler tanımlayarak vestibüler rehabilitasyonun temelini atmıştır ${ }^{7}$. Vestibüler rehabilitasyon, baş dönmesi ve denge bozukluğuna yol açan vestibüler sistem patolojilerinde, hastaların yetersizlik, özürlülük veya engelliliklerinin değerlendirilerek, azaltılmasını amaçlayan egzersiz temelli tedavi şeklidir8. Vestibüler bozuklukların tedavisinin temel dayanağı olan vestibüler rehabilitasyon, baş dönmesi, yaşam kalitesinin iyileşmesine ve dengenin sürdürülmesine olanak tanır. Ayrıca nöroplastisite mekanizmalarını kullanarak, statik-dinamik postüral stabiliteyi, görsel vestibüler etkileşimleri geliştiren ve bakış stabilitesini artıran etkili bir yöntem olarak bilinmektedir`. Vestibüler rehabilitasyon, adaptasyon yoluyla santral sinir sistemi plastisitesini kolaylaştırması, denge bozukluğu olan hastalarda denge mekanizmalarının üretilmesi ile dengeyi iyileştirmesi ve hastaların günlük yaşam aktivitelerine devam etmelerine yardımcı olması amacıyla tasarlanan bir dizi egzersiz olarak da tanımlanabilir ${ }^{8}$. Vestibüler rehabilitasyon, insan beynindeki kompansatuar ve adaptif mekanizmaları harekete geçirmeyi ve hızlandırmayı hedefler. Adaptasyon, habitüasyon, substitüsyon gibi nöroplastisite mekanizmaları, farklı zaman dilimlerinde çeşitli yöntemlerle sağlanabilen rehabilitasyonun etkinliğini vurgular' ${ }^{10}$. Bu yöntem unilateral periferik, santral veya mikst tip vestibüler sistem bozuklukları olan hastalara güvenilir, etkili ve noninvaziv bir tedavi seçeneği sunar ${ }^{11}$. Ayrıca, statik ve dinamik postüral stabiliteyi ve yürümeyi iyileştirir ve baş dönmesi semptomlarını ve buna eşlik eden depresyon ve anksiyete semptomlarını da azaltır ${ }^{12}$. Sonuç olarak vestibüler rehabilitasyon, hastaların özgüvenini ve yaşam kalitesini artırmayı hedefler. Buna karşın hastaların yanlış egzersiz performansı, aktif katılımı ve ilgisinin gerekliliği dahil olmak üzere birçok faktör geleneksel vestibüler rehabilitasyon sonucunu olumsuz yönde de etkileyebilir6. Birçok çalışma, erken dönemde vestibüler rehabilitasyona yönlendirilen hastaların, vestibüler sistem hasarından sonra daha iyi denge performansı sergilediklerini vurgulamıştır13. Bunun sebebi erken rehabilitasyonun, somatosensör ve görsel uyaranlara karşı duyarlı olması sebebiyle daha hızlı iyileşme sağlamasıdır. Bu durumda klinisyen ilk olarak yanlış stratejiyi veya kompanzasyonu engelleyen mekanizmayı tanımlamalı, düzeltmeli ve ikinci olarak hastayı doğru bir stratejiye yönlendirmelidir ${ }^{14}$.

\section{Sanal Gerçeklik}

Sanal gerçeklik, son 20 yılda birçok bilimsel topluluğun ilgisini çekmiştirir ${ }^{15}$. Sanal gerçeklik kavramı ilk olarak 1980'lerin sonlarında Jaron Lanier tarafından tanıtılmıştır. Bilgisayar bilimcisi olan Lanier, kullanıcının özel cihazlar yardımıyla sanal ortamın grafik öğeleriyle etkileşime girmeye başladığı bir grafik arayüzü kullanarak bir bilgisayar modeli inşa etmiştir. Bu ortamı, 
video ve televizyon teknolojisinden ayıran ve sanal gerçekliği bilişim, eğitim, rehabilitasyon, tıp, eğlence, askeri ve uzay teknolojileri gibi çeşitli alanlara uygun kılan en önemli unsur bu etkileşimin var olmasıdır. Sanal gerçekliğin ortaya çıkışı, grafik ve üç boyutlu arayüzlerin ihtiyaçlarını destekleyebilen güçlü bilgisayarların geliştirilmesi teknolojik ilerlemelerle yakından bağlantılıdır ${ }^{16}$.

Sanal gerçeklik, gerçekçi bir dünya yaratmak amacıyla bilgisayar grafiklerini birleştiren, kullanıcının sözel ve sözel olmayan yanıtlarına cevap verebilen ve sanal dünyayı değiştirebilen teknoloji olarak tanımlanır ${ }^{17}$. Günümüzde sanal gerçeklik, dairesel ekran, düz ekran veya başa monte edilen çeşitli görüntüleme biçimlerini kullanarak sanal bir ortam oluşturmak için yaygın olarak kullanılan bir tekniktir ${ }^{18}$. Sanal gerçeklik, gerçek dünyanın bilgisayar tabanlı modellerinin oluşturulmasına izin veren ve insanlara yeni insan-bilgisayar arayüzleri aracılığıyla bu modellerle etkileşim kurmaları için bir araç sağlayan bilimin bir parçası haline gelmiştir ${ }^{19}$. Sanal gerçeklik teknolojisi, bilgisayarlar tarafından oluşturulan ve çeşitli sanal ortamlar aracılığıyla kullanıcılara sunulan gerçek dünyanın etkileşimli simülasyonlarını yansıtır ve aynı zamanda kullanıcıların kendilerini bu ortamlarda mevcut hissetmelerini sağlar ${ }^{6}$. Bu teknolojideki modern bilgisayar grafikleri ve sonikler, gerçeğe yakın bir kullanım oluşturmak için kullanıcının baş ve vücut hareketlerine uygun olarak görsel ve işitsel ekranın anlık güncellemelerine olanak tanır. Sanal gerçeklik teknolojisi, sağlık personelleri için tıbbi eğitim, cerrahi ve teşhis desteği de dâhil olmak üzere çeşitli amaçlar için sağlık hizmetlerinde günden güne sıkça kullanılmaktadır. Aynı zamanda çeşitli hasta grupları için rehabilitasyon ve eğitim amacıyla da sıklıkla kullanılmaktadır ${ }^{19}$. Sanal gerçeklik teknolojisi hastalara adım adım, interaktif, dinamik ve üç boyutlu bir rehabilitasyon ortamı sunar ${ }^{20}$. Sanal gerçeklik tabanlı rehabilitasyonların geleneksel rehabilitasyon yöntemlerine kıyasla motivasyonel ve eğlenceli oluşu, hasta kooperasyonu ve uyumu için önem $\operatorname{taşır}^{18}$. Teknolojinin artan kullanımı vestibüler rehabilitasyon yöntemlerinin çeşitlenmesine katkı sağlamıştır ${ }^{17}$.

\section{Sanal Gerçeklik Temelli Vestibüler Rehabilitasyon}

Vestibüler rehabilitasyon, Cawthorne (1944) ve Cooksey (1946) tarafından tanımlanan geleneksel biçiminin dışında, sanal gerçeklik teknolojisi ile de gerçekleştirilebilir. Bu teknoloji terapötik amaçlar için kullanılabilir ve daha az fiziksel alan gerektirdiğinden profesyonellerin ve kurumların ihtiyaçlarını karşılar7. Bu teknoloji vestibüler egzersizler sırasında simüle edilmiş sürükleyici bir ortamın yaratılmasına izin verir ${ }^{21}$. Sanal gerçeklik teknolojisi, vestibüler rehabilitasyon için adaptasyon, habitüasyon ve substitüsyon egzersizlerini içeren gerçek zamanlı simülasyon, interaktif işlevler ve oyun özellikleriyle donatılabilir. Bu sistemler, kullanıcıları motive edebilecek görsel, işitsel ve dokunsal geri bildirimler sağlayabilir. Ayrıca sanal ortamda fiziksel bir varlık hissi uyandırmasıyla performansın ölçülmesini ve özelleştirilmiş bir eğitim olanağı sağlar ${ }^{11}$.

Sanal gerçeklik temelli vestibüler rehabilitasyon, vestibüler sistem bozuklukları ve hafif travmatik beyin hasarı için etkili bir tedavi yöntemidir ${ }^{12}$. Ayrıca, vestibüler rehabilitasyon yaşlı erişkinlerde dinamik dengeyi ve güveni geliştirebilir ve hastaları çeşitli görsel uyaranlara karşı da duyarsızlaştırabilir ${ }^{11}$. Sanal gerçeklik temelli vestibüler rehabilitasyon baş dönmesi ve psikolojik semptomları iyileştirmenin etkili bir yolunu sunar. Kişinin dengesini geliştirerek, özgüvenin yeniden oluşturulmasına, günlük aktivitelerin gerçekleştirilmesinde bağımsızlık kazanılmasına, anksiyete ve sosyal etkileşimlerin iyileştirilmesine yardımcı olur²2.

Görsel uyaranlara kademeli olarak maruz kalma, bireylerin kışkırtıcı uyaranlara karşı adaptasyona ve semptomların azalmasına yardımcı olur. Vestibüler rehabilitasyonda sanal gerçekliğin kullanımı, görsel, vestibüler ve somatosensöriyel sistemler arasındaki duyusal 
çatışmadan kaynaklanan semptomların duyarsızlaştırılmasını kolaylaştırır ${ }^{23}$. Sanal gerçeklik temelli vestibüler rehabilitasyon yönteminde ortamın algılanma durumu, gerçek dışı bir uyaran tarafından değiştirilir, duyusal bir çatışma oluşturur ve vestibülo-oküler refleksin kazancını değiştirir. Sanal gerçeklik temelli cihazlar, retina üzerinde bir görüntünün tekrarlanan hareketlerini ve vestibüler yanıtların görsel uyarımlarını indükleyebilir7.

Vestibüler rehabilitasyon programı, öğrenme, eğitim ve geri bildirim gerektirir. Geleneksel rehabilitasyon esnasında geri bildirim daha zor gerçekleşir. Böylece sanal gerçeklik temelli vestibüler rehabilitasyon, geleneksel rehabilitasyona kıyasla daha fazla geri bildirime ve daha fazla teşvik edici ve zenginleştirici gelişime izin verir. Denge ve postüral iyileşme, alt ve üst ekstremitelerde daha fazla hareket ve hastanın ilgisini sürdürme gibi faydaları da bulunur7 ${ }^{7}$ Sanal gerçeklik tabanlı cihazlar, habitüasyon, adaptasyon ve substitüsyon sağlama olană̆ı, visual vertigo görülen kişilerde etkinliği ve psikoloji üzerindeki olumlu etkileri nedeniyle birçok klinisyen tarafından vestibüler rehabilitasyonda test edilmiştiriro,24.

Nintendo Wii, klinik ortamda denge değerlendirmesi ve tedavisi için kullanılan ekonomik, yenilikçi ve güvenli bir bilgisayar oyun sistemidir ${ }^{25-27}$. Wiimote ve Wii Fit ise bu oyundan türetilmiş bilgisayar tabanlı bir bakış stabilizasyon egzersizleri eğitimidir. Unilateral vestibüler hipofonksiyonlu bireylerde vestibüler rehabilitasyon sırasında Nintendo Wii Fit Plus ve baş üstü oyun etkinliklerini değerlendirmek ve geleneksel vestibüler rehabilitasyon protokolü ile birleştirildiğinde elde edilen iyileşmeleri ortaya koymak amacıyla randomize kontrollü baş üstü oyun ve Nintendo Wii Fit Plus temelli farklı çalışmalar yapılmıştır13,18. Harekete dayalı etkileşim sistemleri alanında baş üstü oyunlar, göz hizasına yakın konumlanması sebebiyle kullanıcılara görüntüleri yüksek çözünürlükte sunar ve kullanıcıların hareketlerini izler. Bu durum kullanıcıları sanal gerçeklik tarafından oluşturulan ortamın bir parçası gibi hissetmelerini sağlar. Micarelli ve arkadaşları (2017) tarafından yapılan çalışmada katılımcılara geleneksel vestibüler rehabilitasyon ve sanal gerçeklik temelli baş üzeri oyun egzersizleri verilmiştir. Katılımcılara başa monte edilen aparat klinisyen kontrolünde takıldıktan sonra The Track Speed Racing 3D oyunu uygulanmıştır. Çalışma sonunda baş üzeri oyun grubuna dâhil edilen katılımcıların vestibülooküler refleks işlevlerinde daha fazla iyileşme gözlenmiştir. Sanal gerçeklik temelli baş üzeri oyunlar ile uygulanan vestibüler rehabilitasyon yöntemi bireyler için yararlı, maliyeti düşük ve yenilikçi bir tedavi seçeneği sunar ${ }^{13}$. Judith Schomaker ve arkadaşları (2011) tarafindan yapılan çalışmada katılımcılar sanal gerçeklik ortamında görsel-vestibüler motor rekalibrasyon görevi gerçekleştirdiler. Katılımcıların görüşleri baş üzeri oyun sistemleri tarafından sağlanmış ve baş üzeri oyun sistemine yerleştirilen kızılötesi yansıtıcı ile baş konumları ve yönü sürekli izlenerek görsel alan buna uygun olarak güncellenmiştir. Katılımcılara verilen görev, robotik bir tekerlekli sandalye tarafından indüklenen vücut dönüşü esnasında bireyin kollarını ve elini sabit bir şekilde tutmasını içermektedir. Çalışma, ön test aşaması, adaptasyon aşaması ve son test aşaması olmak üzere 3 aşamadan meydana gelmektedir. Katılımcıların performansları ilk olarak rotasyon sırasında hiçbir görsel geri bildirim bulunmayan bir ön test ile ölçülmüştür. Bunu takip eden adaptasyon aşamasında, vücut rotasyonundan kaynaklanan optik akış sağlanmıştır. Bu görsel geri bildirim, gerçekte olduğundan daha küçük bir dönme hareketi yanılsaması yaratmak için manipüle edilmiş ve böylece görsel-vestibüler haritalamayı değiştirmiştir27. Sparrer ve arkadaşları (2013) geleneksel vestibüler rehabilitasyon ve sanal gerçeklik temelli vestibüler rehabilitasyon protokolüne dahil edilen katılımcıların Duyusal Organizasyon Test sonuçlarını karşılaştırmıştır. Sanal gerçeklik temelli vestibüler rehabilitasyon protokülüne dahil edilen grubun Duyusal Organizasyon Test sonuçları, geleneksel vestibüler rehabilitasyon protokolüne dahil edilen grubun sonuçlarına kıyasla daha iyi sonuçlanmıştır ${ }^{28}$. Tabanfar ve arkadaşları (2018) akıllı telefon uygulaması ile sanal gerçeklik gözlüğüne akıllı telefon yerleştirmiş ve sağlıklı 
bireylere evde uygulanabilir sanal gerçeklik ortamında Epley manevrası uygulamıştır. Katılımcıların uygulama kılavuzunu okumalarından sonra destek gerektiren veya kendi kendine uygulanabilen manevralara dâhil edilmek üzere randomize şekilde çalışmaya alınmıştır. Tüm katılımcıların performansları 10 üzerinden puanlanmıştır. Katılımcılar, NASA İş Yükü İndeksini doldurarak algılanan iş yüklerini derecelendirilmiş ve her iki grup için ortalamaları hesaplanmıştır. Sanal gerçeklik temelli Epley manevrasına dâhil edilen katılımcılar, Epley manevrasını kendi kendine uygulayan katılımcılara kıyasla manevrayı istatistiksel olarak anlamlı bir şekilde daha doğru gerçekleştirmiştir. Çalışma sonunda evde uygulanabilir Epley manevralarının doğruluğunu ve etkinliğini artırabilecek ümit verici bir teknoloji olduğu bildirilmiştir. Gelecekteki çalışmalarda klinik etkinliğinin belirlenmesi için geniş BPPV hasta gruplarına ihtiyaç vardır²9.

\section{Sonuç ve Öneriler}

Sanal gerçeklik temelli vestibüler rehabilitasyon, bireyler için ilgi çekici ve güvenilir bir ortam sunar. Sanal gerçeklik teknolojisine dayalı etkileşimli sistemler, vestibüler rehabilitasyonu geliştirmek için umut vaat etmektedir. Gelecekteki çalışmalar yan etkilerini ortaya koymalı, sanal gerçeklik temelli vestibüler rehabilitasyonu, geleneksel vestibüler rehabilitasyon yöntemleri ile karşılaştırmalı ve bu yöntemlerin maddi maliyetlerini ve faydalarını değerlendirmelidir. Ek olarak, farklı türdeki sanal gerçeklik egzersizlerinin etkinliğini incelemek için sürükleyici ve sürükleyici olmayan egzersizlerin kullanımını karşılaştırmalıdır. Son olarak, ek araştırmalar, uzun vadeli müdahale ve takibin vestibüler rehabilitasyon sonuçları üzerindeki etkisini ele almalıdır. Bununla birlikte, popülasyon seçimi, müdahale tasarımı ve kanıta dayalı klinik sonuçlar açısından literatürde sınırlılıklar mevcuttur. Gelecekteki çalışmalar bu sınırlamaları ele almayı da amaçlamalıdır.

\section{KAYNAKLAR}

1. Khan S, Chang R. Anatomy of the vestibular system: A

Review. Neurorehabilitation, 2013;32(3):437-443. https://doi.org/10.3233/NRE-130866.

2. Smith PF. The vestibular system and cognition. Current Opinion in Neurology. 2017;30(1):84-89. https://doi.org/10.1097/WC0.0000000000000403.

3. Tascioglu AB. Brief review of vestibular system anatomy and its higher order projections. Neuroanatomy. 2005;4:24-27.

4. Bispo AS, Silva LS, Pinto MVM, Baraúna MA, Silva CM, Costa DA. Vestibular system and postural control. https://www.efdeportes.com/efd149/vestibular-system-and-posturalcontrol.htm. Published October 2010.

5. Fernandez L, Breinbauer HA, Delano PH. Vertigo and dizziness in the elderly. Frontiers in Neurology. 2015;6:144-150. https://doi.org/10.3389/fneur.2015.00144

6. Bergeron M, Lortie CL, Guitton MJ. Use of virtual reality tools for vestsis. Advances in Medicine. 2015;1-9. https://doi.org/10.1155/2015/916735.

7. Ardıç FN. Vertigo. 2. baskı. İstanbul: US Akademi; 2019.

8. Miziara OC, Oliveira VR, Gasparini ALP, et al. Virtual reality in vestibular rehabilitation: a pilot study. International Journal of Therapy and Rehabilitation. 2019;26(7):1-13. https://doi.org/10.12968/ijtr.2018.0056. 
9. Marioni G, Fermo S, Zanon D, Broi N, Staffieri A. Early rehabilitation for unilateral peripheral vestibular disorders: A prospective, randomized investigation using computerized posturography. European Archives of Oto-Rhino-Laryngology. 2013;270(2):425-435. https://doi.org/10.1007/s00405-012-1944-4.

10. Micarelli A, Viziano A, Bruno E, Micarelli E, Augimeri I, Alessandrini M. Gradient impact of cognitive decline in unilateral vestibular hypofunction after rehabilitation: preliminary findings. European Archives of Oto-Rhino-Laryngology. 2018;275(10):2457-2465. https://doi.org/10.1007/s00405-018-5109-y .

11. Viziano A, Micarelli A, Augimeri I, Micarelli D, Alessandrini M. Long-term effects of vestibular rehabilitation and head-mounted gaming task procedure in unilateral vestibular hypofunction: a 12-month follow-up of a randomized controlled trial. Clinical Rehabilitation. 2019;33(1):24-33. https://doi.org/10.1177/0269215518788598.

12. Hsu SY, Fang TY, Yeh SC, Su MC, Wang PC, Wang VY. Three dimensional, virtual reality vestibular rehabilitation for chronic imbalance problem caused by ménière's disease: a pilot study. Disability and Rehabilitation. 2017;39(16):1601-1606. https://doi.org/10.1080/09638288.2016.1203027.

13. Micarelli A, Viziano A, Augimeri I, Micarelli D, Alessandrini M. Three-dimensional headmounted gaming task procedure maximizes effects of vestibular rehabilitation in unilateral vestibular hypofunction: A randomized controlled pilot trial. International Journal of Rehabilitation Research. 2017;40(4):325-332. https://doi.org/10.1097/MRR.0000000000000244.

14. Park JH, Jeon HJ, Lim EC, et al. Feasibility of eye tracking assisted vestibular rehabilitation strategy using immersive virtual reality. Clinical and Experimental Otorhinolaryngology. 2019;12(4):376-384. https://doi.org/10.21053/ceo.2018.01592.

15. Scherer M, Schubert MC. High-velocity angular vestibulo-ocular reflex adaptation to position error signals. Journal of Neurologic Physical Therapy. 2010;34(2):82-76. https://doi.org/10.1097/NPT.ob013e3181dde7bc.

16. Bush ML, Dougherty W. Assessment of vestibular rehabilitation therapy training and practice patterns. Journal of Community Health. 2015;40(4):802-807. https://doi.org/10.1007/s10900-015-0003-7.

17. Valentina M, Ana Š, Valentina M, Martina Š, Željka K, Mateja, Z. Virtual reality in rehabilitation and therapy. Acta Clinica Croatica. 2013; 52(4):453-457.

18. Meldrum D, Herdman S, Vance R, et al. Effectiveness of conventional versus virtual reality-based balance exercises in vestibular rehabilitation for unilateral peripheral vestibular loss: results of a randomized controlled trial. Archives of Physical Medicine and Rehabilitation. 2015;96(7):1319-1328. https://doi.org/10.1016/j.apmr.2015.02.032.

19. Rosiak O, Krajewski K, Woszczak M, Jozefowicz-Korczynska M. Evaluation of the effectiveness of a virtual reality-based exercise program for unilateral peripheral vestibular deficit. Journal of Vestibular Research. 2018;28(5-6):409-415. https://doi.org/ 10.3233/VES-180647. 
20. Lányi CS. Virtual reality in healthcare. In: N. Ichalkaranje, A. Ichalkaranje, eds. Intelligent Paradigms for Assistive and Preventive Healthcare. Berlin, Heidelberg: Springer; 2006:87-116.

https://www.researchgate.net/publication/225733524 Virtual Reality in Healthcare. https://doi.org/10.1007/11418337 3 .

21. Dennison MS, Wisti AZ, D’Zmura M. Use of physiological signals to predict cybersickness. Displays. 2016;44(1):42-52. https://doi.org/10.1016/j.displa.2016.07.002 .

22. Xie M, Zhou K, Patro N, et al. Virtual Reality for vestibular rehabilitation: A systematic review. Otology \& Neurotology. 2021;42(7):967-977. https://doi.org/10.1097/MAO.0000000000003155.

23. Zeigelboim BS, José MR, Santos GJBD, et al. Balance rehabilitation with a virtual reality protocol for patients with hereditary spastic paraplegia: Protocol for a clinical trial. PLOS ONE. 2021;16(4). https://doi.org/10.1371/journal.pone.0249095.

24. Alahmari KA, Sparto PJ, Marchetti GF. Comparison of virtual reality based therapy with customized vestibular physical therapy for the treatment of vestibular disorders. IEEE Transactions on Neural Systems and Rehabilitation Engineering. 2013;22(2):389-399. https://doi.org/10.1109/TNSRE.2013.2294904.

25. Chen PY, Hsieh WL, Wei SH, Kao CL. Interactive wiimote gaze stabilization exercise training system for patients with vestibular hypofunction. Journal of NeuroEngineering and Rehabilitation. 2012;9(1):77. https://doi.org/10.1186/1743-0003-9-77.

26. Van KG, Mert A, De Ru JA. Treatment of vertigo and postural instability using visual illusions. The Journal of Laryngology \& Otology. 2014;128(11):1005-1007. https://doi.org/10.1017/So022215114002254.

27. Burns MK, Andeway K, Eppenstein P, Ruroede K. Use of the wii gaming system for balance rehabilitation: Establishing parameters for healthy individuals. Games For Health Journal. 2014;3(3):179-183. https://doi.org/10.1089/g4h.2013.0067.

28. Sparrer I, Duong Dinh, TA, Ilgner J, Westhofen M. Vestibular rehabilitation using the nintendo $\AA$ wii balance board - a user-friendly alternative for central nervous compensation. Acta Oto-Laryngologica. 2013;133(3):239-245. https://doi.org/10.3109/00016489.2012.732707.

29. Tabanfar R, Chan HH, Lin V, Le T, Irish, JC. Development and face validation of a virtual reality epley maneuver system (VREMS) for home epley treatment of benign paroxysmal positional vertigo: A randomized, controlled trial. American Journal of Otolaryngology 2018;39(2):184-191. https://doi.org/10.1016/j.amjoto.2017.11.006. 